\title{
LA LABOR DE BETTY MOLESWORTH ALLEN
}

\author{
E. FERNANDEZ GALIANO
}

\begin{abstract}
Florecía la primavera de 1966 cuando una importante noticia circulada por los medios botánicos europeos sorprendió (y, en algunos casos, hizo palidecer de envidial a los españoles estudiosos de los vegetales. En un rincón de la revista Taxon, en la sección News and Notes (15: 82, 1966), figuraba una nota en la que, mediante 18 escuetas lineas, se daba cuenta de uno de los hallazgos corológicos más importantes de los últimos tiempos para la botánica europea. Y al pie de la nota, la firma: B. Molesworth Allen, Los Barrios, Prov. Cádiz.
\end{abstract}

Poco después, casi simultáneamente, The British Fern Gazette (9, 7, 1966) publicaba un breve artículo, más detallado, en el que su autora daba noticia más amplia del singular descubrimiento: "In January 1965 I found near Algeciras in southern Spain a colony of Psilotum nudum (L.) Griseb. growing in a rock crevice".

No obstante esta aclaración, para la mayoría de nosotros continuaba todavia flotando la incógnita sobre la personalidad de la autora del notable hallazgo que había conmocionado a los botánicos españoles. Poco a poco, de unos y otros, íbamos reuniendo información sobre la protagonista del descubrimiento que estimulaba todavía más nuestra curiosidad.

Incorporado a la Universidad de Sevilla a finales de 1965, tenía la intención de ponerme en contacto cuanto antes con Mrs. Allen, pero las complicadas tareas de instalación y organización del Departamento de Botánica fueron aplazando mi iniciativa. Finalmente, fue en mayo de 1967, con motivo de la celebración en Sevilla del V Simposio de la Flora Europea, cuando conocí personalmente a Betty Molesworth-Allen, estableciendo desde entonces una relación que cristalizó en una sólida amistad materializada en muchas visitas a Los Barrios y en una voluminosa carpeta que encierra un epistolario que conservo cuidadosamente y que comienza por una carta del 20 de junio de 1967 en la que, en un castellano bastarite pintoresco y no exento de cierta gracia, me agradecía el haber sido admitida al Simposio, donde había aprendido mucho durante las conferencias eruditas. A partir de esta carta, la liberé de tener que escribir en español y toda nuestra correspondencia se desarrolló escribiendo cada uno en su propia lengua. Sus cartas, de minúscula y apretada letra y muchas veces sin fecha concreta (Feb., 24th, por ejemplo), son un compendio de atinadisimas observaciones y sugerencias, comunicándome frecuentemente, .con insólita generosidad, nuevos descubri- 
mientos que, en manos desaprensivas, hubieran bastado para cimentar la buena fama de algún ambiciosillo aspirante a botánico. Pero ella se ha mantenido siempre por encima de esas pequeñas ruindades, quizás pensando que lo importarite es ser útil, no importa a quien.

A pèsar de haber establecido ya relación con Mrs. Allen, mi curiosidad no se encontraba todavía satisfecha, pues deseaba conocerla en su propio ambiente, en la comarca de sus correrías botánicas. Ella, por su parte, ardía en deseos de mostrarme sus hallazgos, consultarme sus dudas (de las que ella conocía casi siempre bastante más que yo), en una palabra, satisfacer esa necesidad que tiene el científico, el investigador, de comunicar a alguien sus ideas sus problemas o sus proyectos.

Por todo ello, un caluroso día de junio de 1967, marché hacia Los Barrios acompañado de algunos de mis colaboradores, con objeto de visitar a la ilustre botánica y satisfacer al propio tiempo mi gran intriga.

Vivia entonces en una encantadora casa, un tanto rústica, bautizada con el sugestivo nombre de Villa Coca, situada al borde de la carretera que une Algeciras con Jerez. No nos costó gran trabajo encontrar el lugar, donde Betty nos esperaba para presentarnos a su marido, Geoffrey, un jovial y expertísimo fotógrafo de animales cuyas fotografías se encuentran reproducidas en diversas revistas de divulgación del mundo, que inmediatamente nos ofreció, obsequioso, unas bebidas que, por supuesto, no rechazamos sino que tomamos ávidamente para restaurar nuestras fuerzas un tanto quebrantadas por el calor del viaje. Recuerdo perfectamente la casa, con una amplia sala de estar de ventanas orientadas a poniente, desde donde se divisaban las lomas de la Sierra del Niño cubiertas de la vegetación color verde oscuro que caracteriza la comarca. La mesa de trabajo, en un aparente desorden en el que se mezclaban periódicos y revistas inglesas con pliegos de plantas, libros, aparatos fotográficos, lentes de aproximación, teleobjetivos... La conversación, amena y generalizada, versó sobre su instalación en las cercanías de Algeciras, donde tenían muchos amigos, después de la jubilación de Geoffrey como funcionario colonial tras no se cuantos años de estancia en Malasia. Ignoro por qué, en aquellos momentos, cruzaron por mi imaginación algunos de los personajes de alguna novela de Sommerset Maugham.

El motivo primario de nuestra visita era conocer la localidad del Psilotum nudum, entonces ignorada por casi todo el mundo y hoy demasiado conocida, por desdicha. Y allá fuimos, guiados por nuestra amiga que se mostró infatigable trepando por los riscos y colándose por vericuetos de tal manera que apenas podíamos seguirla. Al final, estaba fatigada, pero en su rostro brillaba el contento.

Desde entonces, muchas visitas y un copioso epistolario, testimonio de una sólida amistad, me permitieron comprobar aspectos notables de su interesante personalidad. La lectura de sus cartas evidencia rasgos de su carácter que es justo hacer resaltar. Ante todo, un amor apasionado por la Naturaleza, en general, y por la Botánica, en particular: This year, fields of Narcissus serotinus appeared all around us, me escribia un mes de noviembre. Se mantenía vigilante sobre la comarca de Los Barrios preocupándose por la conservación de sus animales y plantas y mostrábase a veces irritada por la intrusión de más de un irresponsable recolector furtivo que asoló 
poblaciones de interesantísimas especies, probablemente con fines lucrativos, lo que nos obligó, más de una vez, a tomar precauciones. Contrasta este censurable proceder con el de nuestra amiga que, descrubridora ella del Psilotum, me escribía refiriéndose a su planta: May I take a specimen of the plant for Leicester University ? I do not like to take it unless I have your permissión. I would be careful. O cuando explica que envía una nota para su publicación, referente al hallazgo de Culcita macrocarpa: for obvious reasons, I did not put the exact locality on the Culcita label. Do you agree that we should be careful about telling people of this locality ? Otras veces, especialmente cuando me daba cuenta de alguna novedad, escribía con buen humor: I have found some interesting places during this long dry weather, and I look forward to returning to them you and Dr. Valdés. In one Sierra I have found Pteris sp. almost certainly serrulata. This is most exciting and naturally I am most anxious you should see it soon... in case they are eaten by your friends, the goats! Shall we have an anti-goat fence around it?

Y así, conocedora palmo a palmo del territorio de las cercanías de Algeciras, explora incansable, comunicándonos contínuos hallazgos, tan interesantes como Cyclosorus dentatus, Pteris serrulata, Thelypteris palustris, Diplazium caudatum, Trichomanes speciosum, entre las pteridofitas, que pertenecen a su especialidad; pero tambien de fanerógamas, como el meritorio descubrimiento de Arisarum proboscideum, cuya presencia en España, tras haber sido ignorada por Willkomm, había sido ya poco menos que desechada. Y tantas otras plantas críticas o interesantes para Andalucía occidental cuya enumeración sería interminable. Todas ellas eran comunicadas a Sevilla con generosidad y desprendimiento notables, mandando ejemplares para el herbario acompañados de cuidadosas etiquetas repletas de datos, como ésta que transcribo, tomada al azar entre muchas otras: Ambrosia maritima L. ? Annual. Deep roots in sand, in colonies higher than $50 \mathrm{~cm}$. Many seedlings. Leaves grey, unpleasanty aromatic (of fish-stale). Male flowers cream. Much branched when adult. In deep sand behind beach with Oenothera stricta, Pycnomon rutifolium, etc. Guadarranque, S. Roque Dist.

Se ha especulado, en ocasiones, sobre los botánicos profesionales y los aficionados a la Botánica y algunos de aquellos menospreciaron a éstos últimos, o algunos de éstos envidiaron aquellos, pretendiendo que disfrutaban de posiciones más destacadas. Sería difícil, atendiendo a estos trasnochados criterios, encajar a Betty Molesworth-Allen en uno de estos dos campos tan frivolamente delimitados. Más bien, ella nos demuestra que la frontera es artificiosa, establecida por mentes cicateras y poco clarividentes. No existe división entre botánicos profesionales y aficionados a la Botánica, sino que todos juntos pueden integrarse dentro del grupo de estudiosos de las plantas, cada uno con intensidad acorde con sus fuerzas, su tiempo o sus posibilidades, sin importar su situación administrativa. Poco se diferencia nuestra amiga, en sus publicaciones y aportación al progreso de la ciencia, de algunos "profesionales" de la Botánica, salvo para aventajarles en muchos aspectos. Asi lo demuestran sus trabajos sobre helechos malayos (1964-1968) o sobre frutos de Malasia, o las plantas interesantes de la jungla, publicados con anterioridad a su asentamiento entre nosotros. Posteriormente, más de una decena de interesantes notas sobre la flora del sur de nuestra península confirman su valía. Lo único que distingue a este tipo de botánicos de los llamados profesionales es la generosidad y el amor por la ciencia, a cuyo cultivo se dedican sin recibir a cambio más 
que la satisfacción por el trabajo bien hecho y por su contribución a la cultura. Recuerdo que en una ocasión, comentando las dificultades políticas que llevaron al cierce de la frontera española con Gibraltar, me decía Betty: "Lo siento por la Biblioteca, pues en Gibraltar hay una muy buena que nos prestaba libros y ahora eso no será posible". Esta anécdota da la medida de la dimensión intelectual de nuestra amiga.

Ahora, con motivo de la reunión de pteridólogos celebrada en Algeciras en octubre de 1980, se ha querido rendir un homenaje a esta infatigable trabajadora, reconociéndole sus méritos y entregándole una placa que dice: Los Ayuntamientos del Campo de Gibraltar a la Profesora B. M. Allen en reconocimiento a la labor botánica realizada en esta comarca. Reunión Internacional de Pteridología. Algeciras, 11 al 14 de octubre de 1980. Alegra pensar que, esta vez, el homenaje ha sido oportuno. Creo expresar el deseo de muchos botánicos españoles, los que asistieron a la reunión y los que no pudimos hacerlo, de solidarizarnos con los organizadores reconociendo lo mucho que, calladamente, ha contribuido Betty al conocimiento de la flora de nuestro pais.

Entre las muchas cosas perdidas al abandonar Andalucía para trasladarme a la Universidad de Madrid, ocupa un destacadísimo lugar haber disminuido mi trato con esta admirada colega que ahora, lógicamente, se ha convertido en menos frecuente por razón de lejanía. Conocedor como pocos de su gran modestia, estoy convencido de que se sentirá incómoda al leer estas líneas, pero no sería fiel a mí mismo y traicionaría la propia esencia de tan justificado homenaje si no pusiera en evidencia las facetas meritorias de su singular $y$ eficaz personalidad.

\section{TRABAJOS PUBLICADOS POR B. MOLESWORTH-ALLEN}

1.- 1953 - Some commion Ferns of the Open Country. I. Malayan Nature Society Journal, 8: 95-106.

2.- 1954 - Some common Ferns of the Open Country. II. Malayan Nature Society Journal, 8: 133-155.

3.- 1957 - Some common Trees of Malaya. Eastern University Press.

4.- 1957. - Some Botanical Books for Malaya. Malayan Nature Society Journal, 13: 73-79.

5.- 1959 - Malayan Fern Notes. I. Garden's Bulletin Singapore, 17: 251-252.

6.- 1959 - Malayan Fern Notes. II. Garden's Bulletin Singapore, 17: 253-272.

7.- 1961 - Some Conservations Problems of Malaya's Hill Station. In Nature conservation in Malaysia: 52-55. Caxton Press.

8. - 1961 - Limestone Hills near Ipoh. In Nature Conservation in Malaysia: 68-72. Caxton Press.

9.- 1963 - Ferns of the Quartz Ridges. Malayan Nature Society Journal, 17: 1932 .

10.- 1964 - Malayan Fern Notes. III. Garden's Bulletin Singapore 20: $381-386$.

11. - 1964 - Descriptions of the Malayan species of Laportea. Garden's 
Bull. Singapore, 20: 361-368.

12.- 1964 - Jelatang and Pulutus. Stinging trees of Malaya. Malayan Nature Society Journal, 18: 3-14.

13.- 1965 - Notes of ferns and birds. Malayan Nature Society Journal, 19: $141-143$.

14.- 1965 - Malayan Fern Notes. IV Garden's Bull. Singapore, 21: 187-194.

15.- 1966 - Interesting Jungle Plants. Malayan Nature Society Journal, 19: 303-304.

16.- 1966 - Piper aduncum in Malayan. Malayan Nature Society Journal, 19: 307.

17.- 1966 - Psilotum nudum in Europe. Taxon, 15: 82.

18. - 1966 - Psilotum nudum in Europe. Brit. Fern Gaz. vol. IX (7): 249-250.

19.- 1967 - Malayan Fruits. Donald Moore Presl Lid. Singapore. 245 págs.

20.- 1967 - Malayan fern Notes. V. Garden's Bull. Singapore, 22: 173-180.

21.- 1967 - Nota preliminar sobre Pteris serrulata Forsk. en España. Anal. Univ. Hispalense, 28: 149-151.

22. - 1967 - The Tree-ferns of Malaya. Garden's Bulletin Singapore, 22: 41-51. (En col. con R.E. HOLTTUM).

23.- 1968 - Interesting jungle plants. Malayan Nat. Jour., 21: 2933:

24.- 1968 - Observations on two spanish ferns. Brit. Fern Gaz., 10: 33-34.

25.- 1968 - Pteridium aquilinum on limestone. Brit. Fern Gaz., 10: $34-36$.

26.- 1969 - Notes on some Malayan Ferns (Adiantum). Malayan Nature Society Journal, 22: 81-85.

27.- 1969 - Nota sobre la presencia de Cyclosurus dentatus en Europa. Bol. Real Soc. Esp. Hist. Nat. (Biol.), 67: 75-76.

28.- 1971 - Nota sobre helechos españoles. Lagascalia, 1: 83-87.

29.- 1971 - Notes on two species of Arisarum in South-West Spain. Kew Bull., 26: 59-60.

30. - 1971 - La presencia de Culcita macrocarpa Presl. en la provincia de Cádiz. Bol. Real Soc. Esp. Hist. Nat. (Biol.), 68: 189197. (En col. con E.F. GALIANO).

31.- 1975 - A note on the distribution of Isoetes in the Cadiz province, Spain. Fern Gaz., 11: 163-164.

32,- 1975 - Common Malaysian Fruits. Malaysian Nature Handbook. Longman. 64 pags.

33.- 1976 - Notas sobre algunas plantas de la provincia de Cádiz. Lagascalia, 6: 239-242.

34.- 1976 - Observations on some are Spanish ferns in Cadiz pronvince, Spain. Brit. Fern Gaz., 11: 271-275.

Dirección del autor: Departamento de Botánica, Facultad de Biología, Universidad Complutense, Madrid. 